\title{
Metered-dose inhalers vs. nebulization for the delivery of albuterol in pediatric asthma exacerbations: a systematic review with meta-analysis
}

\author{
Laura Payares-Salamanca ${ }^{1}$, Sandra Contreras-Arrieta ${ }^{2}$, Victor Florez-Garcia ${ }^{1}$, Alexander \\ Barrios-Sanjuanelo ${ }^{1}$, Ivan Stand-Niño ${ }^{1}$, and Carlos Rodriguez-Martinez ${ }^{3}$ \\ ${ }^{1}$ Universidad del Norte \\ ${ }^{2}$ Universidad del Sinu Elias Bechara Zainum Escuela de Medicina \\ ${ }^{3}$ School of Medicine, Universidad El Bosque
}

June 17, 2020

\begin{abstract}
Objectives: Although albuterol, the most frequently used bronchodilator, has been traditionally and generally delivered via nebulization (NEB) with compressed air/oxygen, the benefits of metered-dose inhalers with a spacer (MDI+S) have been widely recognized as an alternative method for albuterol administration. The aim of this systematic review was to compare the response to albuterol delivered through NEB with albuterol delivered through MDI+S in pediatric patients with asthma exacerbations. Methods: We conducted an electronic search in MEDLINE/PubMed, EMBASE, Ovid and ClinicalTrials. To be included in the review, a study had to a randomized clinical trial comparing albuterol delivered via NEB versus MDI+S; and had to report the rate of hospital admission (primary outcome), or any of the following secondary outcomes: oxygen arterial saturation, heart rate (HR), respiratory rate, the pulmonary index score (PIS), adverse effects, and need for additional treatment. Results: Fifteen studies $(\mathrm{n}=2057)$ met inclusion criteria. No significant differences were found between the two albuterol delivery methods in terms of hospital admission (RR $0.89 ; 95 \%$ CI 0.55 to $1.46 ; \mathrm{I} 2=32 \%$; $=0.65$ ). There was a significant reduction in the PIS score (MD -0.63; 95\% CI -0.91 to $-0.35 ;$ I2=0\%; p < 0.00001), and a significantly smaller increase in HR (better) (MD -6.47; $95 \%$ CI -11.69 to -1.25 ; $\mathrm{I}=0 \%$; $=0.02$ ) when albuterol was delivered through MDI+S than when it was delivered through NEB. Conclusions: This review showed a significant reduction in the PIS and a significantly smaller increase in HR when albuterol was delivered through MDI+S than when it was delivered through NEB.
\end{abstract}

\section{Hosted file}

Main Document.doc available at https://authorea.com/users/334430/articles/460410-metereddose-inhalers-vs-nebulization-for-the-delivery-of-albuterol-in-pediatric-asthmaexacerbations-a-systematic-review-with-meta-analysis

\section{Hosted file}

Table 1.doc available at https://authorea.com/users/334430/articles/460410-metereddose-inhalers-vs-nebulization-for-the-delivery-of-albuterol-in-pediatric-asthmaexacerbations-a-systematic-review-with-meta-analysis 


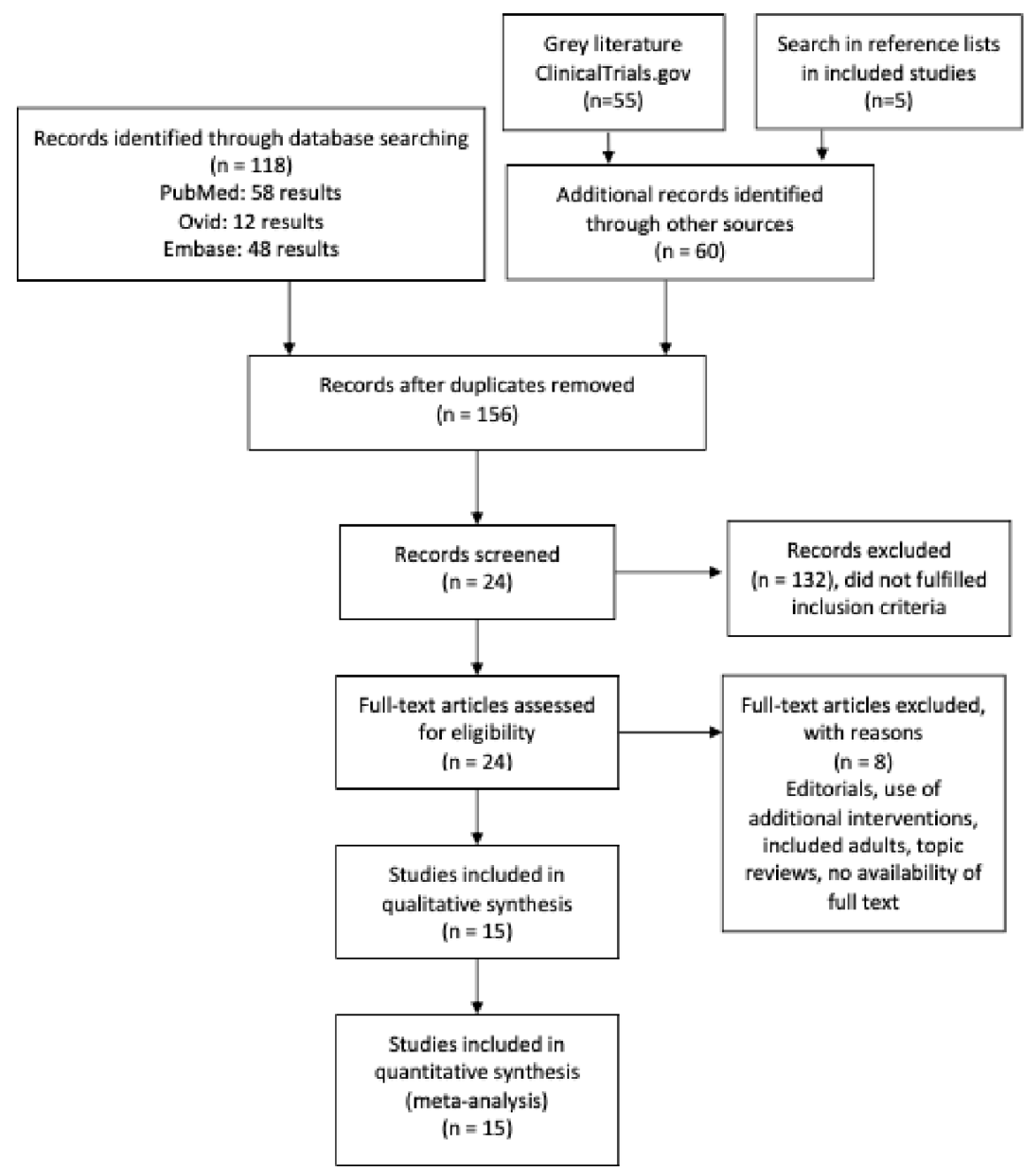




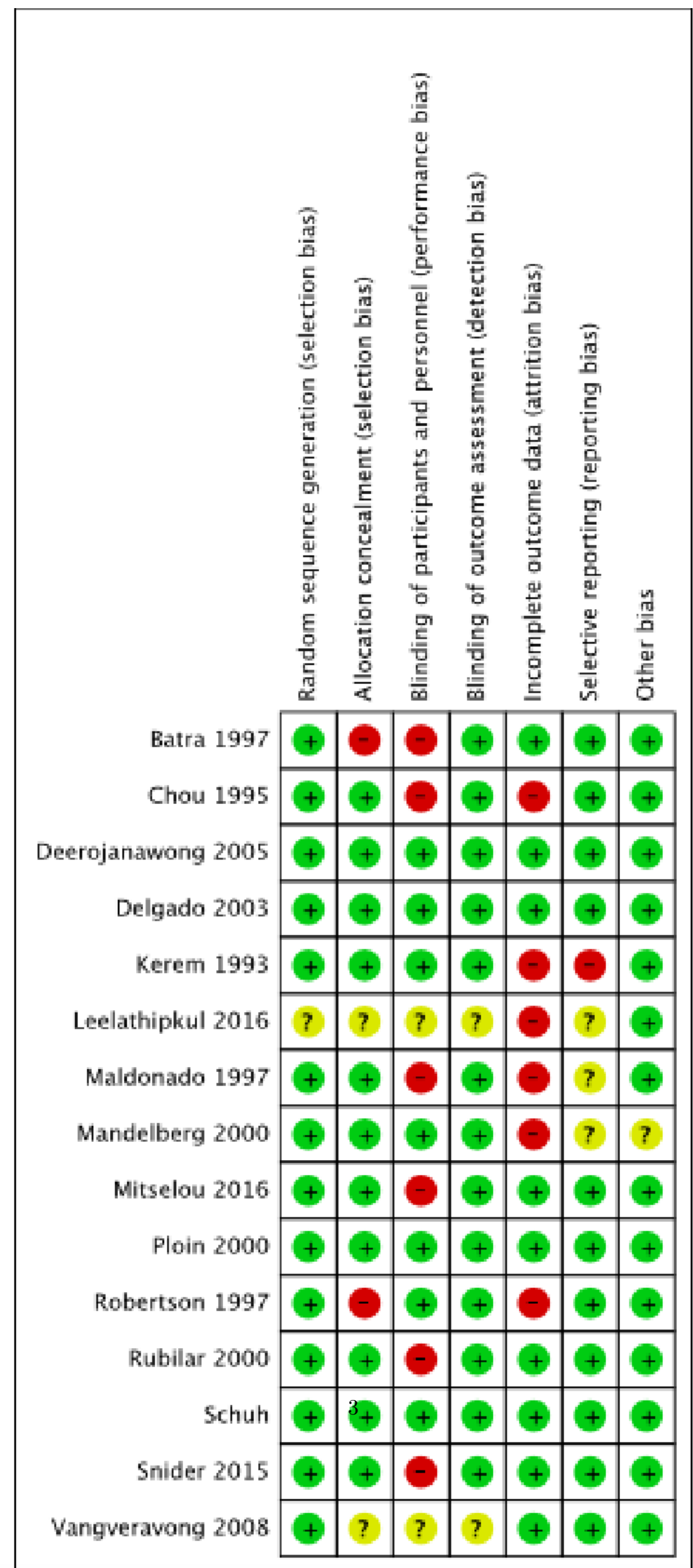



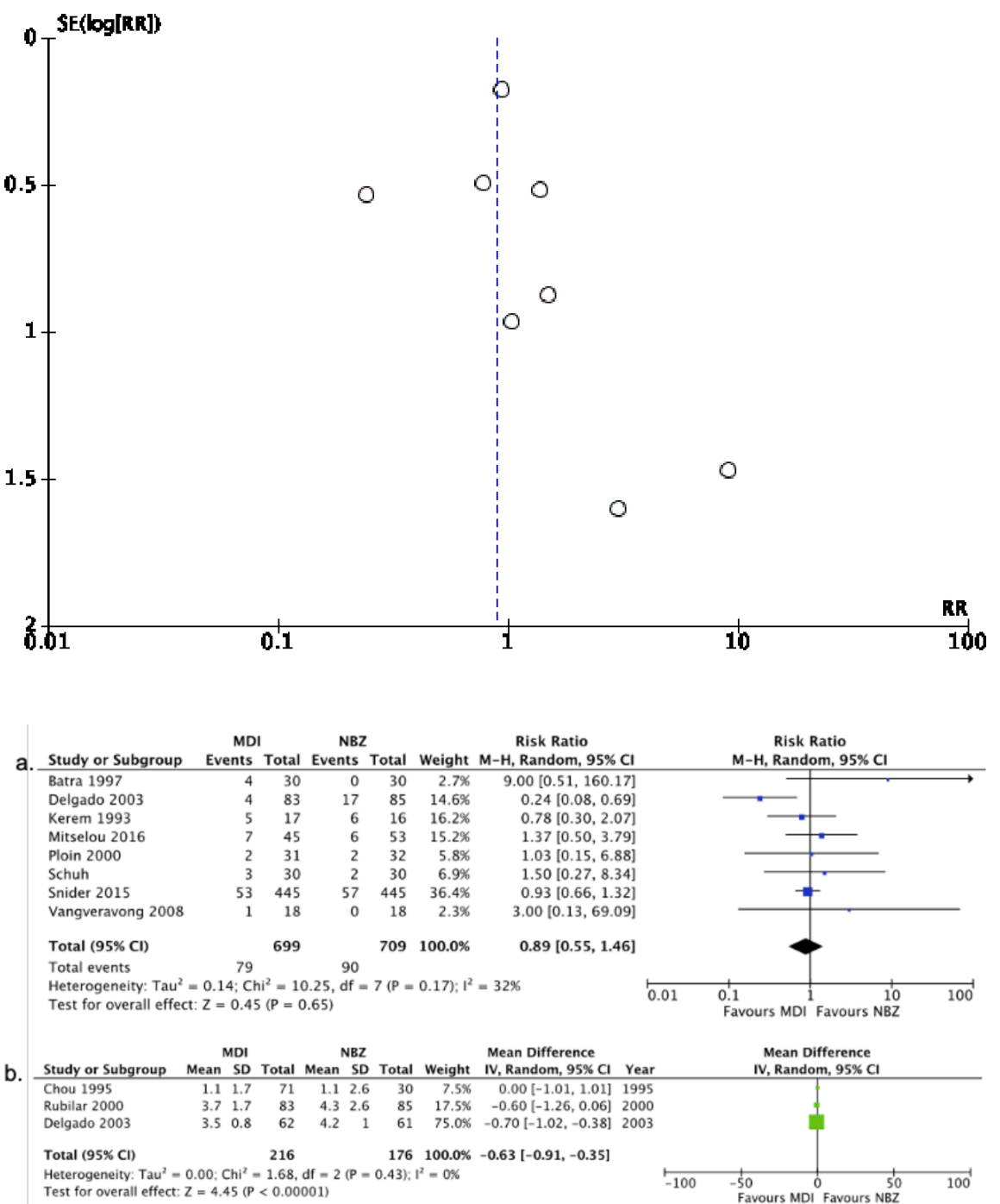

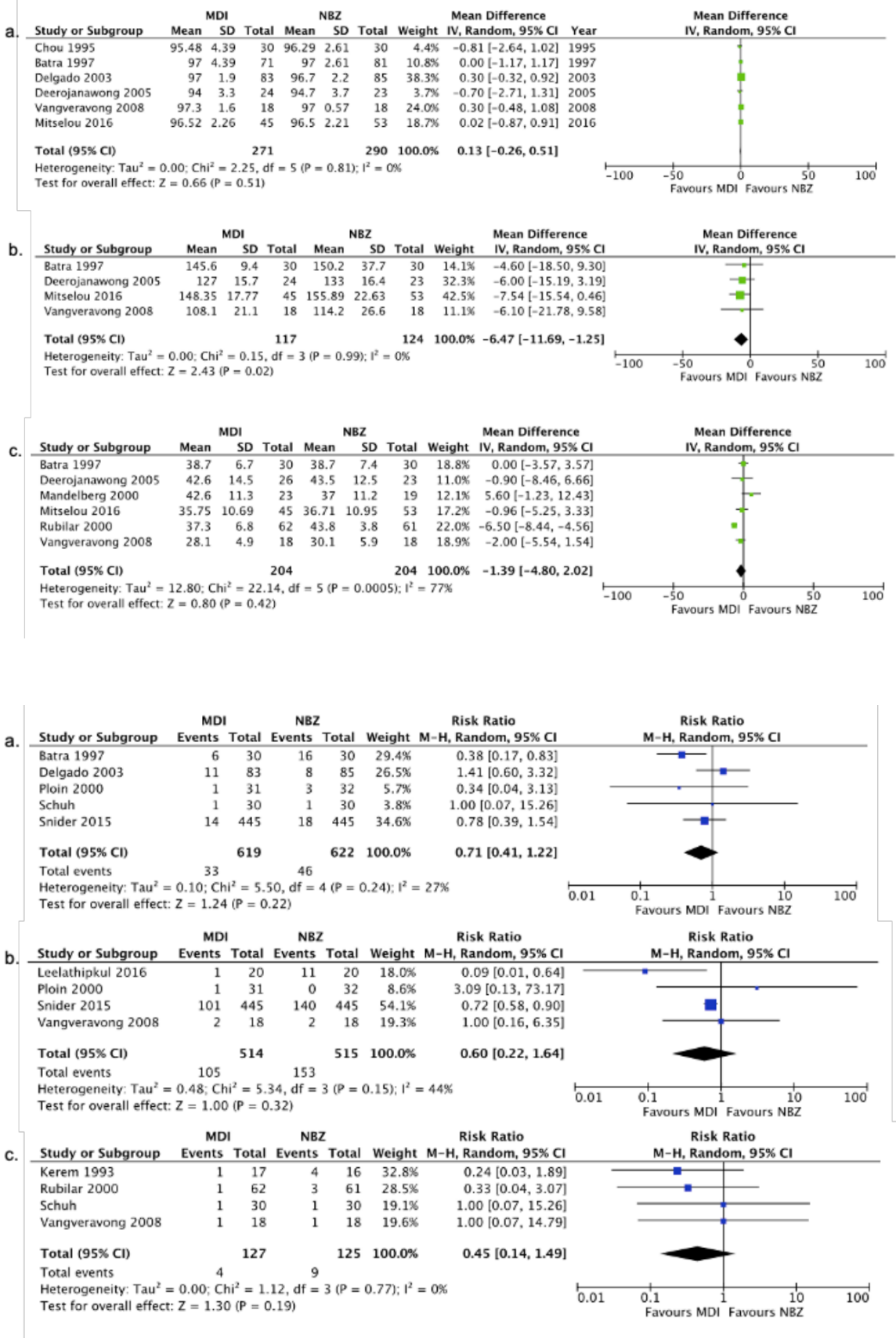